\title{
Article
}

\section{SREBP-1c Deficiency Affects Hippocampal Micromorphometry and Hippocampus-Dependent Memory Ability in Mice}

\author{
Mary Jasmin Ang ${ }^{1,2,+}\left(\mathbb{D}\right.$, Sueun Lee ${ }^{1,3,+}{ }^{\mathbb{C}}$, Mai Wada ${ }^{1}$, Poornima D. E. Weerasinghe-Mudiyanselage ${ }^{1}$, \\ Sung-Ho Kim ${ }^{1}$, Taekyun Shin ${ }^{4}\left(\mathbb{D}\right.$, Tae-Il Jeon ${ }^{5}$, Seung-Soon $\operatorname{Im}^{6}{ }^{\mathbb{D}}$ and Changjong Moon ${ }^{1, *} \mathbb{C}$ \\ 1 Department of Veterinary Anatomy and Animal Behavior, College of Veterinary Medicine and BK21 FOUR \\ Program, Chonnam National University, Gwangju 61186, Korea; 166371@jnu.ac.kr (M.J.A.); \\ leese@kiom.re.kr (S.L.); wataametokatatumuri@gmail.com (M.W.); 208314@jnu.ac.kr (P.D.E.W.-M.); \\ shokim@chonnam.ac.kr (S.-H.K.) \\ 2 Department of Basic Veterinary Sciences, College of Veterinary Medicine, University of the Philippines Los \\ Baños, Los Baños 4031, Philippines \\ 3 Herbal Medicine Resources Research Center, Korea Institute of Oriental Medicine, Naju 58245, Korea \\ 4 Department of Veterinary Anatomy, College of Veterinary Medicine, Jeju National University, \\ Jeju 63243, Korea; shint@jejunu.ac.kr \\ 5 Department of Animal Science, College of Agriculture and Life Science, Chonnam National University, \\ Gwangju 61186, Korea; tjeon@chonnam.ac.kr \\ 6 Department of Physiology, Keimyung University School of Medicine, Daegu 42601, Korea; ssim73@kmu.ac.kr \\ * Correspondence: moonc@chonnam.ac.kr; Tel.: +82-62-530-2838 \\ + First two authors (M.J.A. and S.L.) contributed equally to this work.
}

\section{check for} updates

Citation: Ang, M.J.; Lee, S.; Wada, M.; Weerasinghe-Mudiyanselage, P.D.E.; Kim, S.-H.; Shin, T.; Jeon, T.-I.; Im, S.-S.; Moon, C. SREBP-1C Deficiency Affects Hippocampal Micromorphometry and Hippocampus-Dependent Memory Ability in Mice. Int. J. Mol. Sci. 2021, 22, 6103. https://doi.org/10.3390/ ijms22116103

Academic Editor: Volkmar Lessmann

Received: 22 April 2021

Accepted: 4 June 2021

Published: 5 June 2021

Publisher's Note: MDPI stays neutral with regard to jurisdictional claims in published maps and institutional affiliations.

Copyright: (C) 2021 by the authors Licensee MDPI, Basel, Switzerland. This article is an open access article distributed under the terms and conditions of the Creative Commons Attribution (CC BY) license (https:// creativecommons.org/licenses/by/ $4.0 /)$.

\begin{abstract}
Changes in structural and functional neuroplasticity have been implicated in various neurological disorders. Sterol regulatory element-binding protein (SREBP)-1c is a critical regulatory molecule of lipid homeostasis in the brain. Recently, our findings have shown the potential involvement of SREBP-1c deficiency in the alteration of novel modulatory molecules in the hippocampus and occurrence of schizophrenia-like behaviors in mice. However, the possible underlying mechanisms, related to neuronal plasticity in the hippocampus, are yet to be elucidated. In this study, we investigated the hippocampus-dependent memory function and neuronal architecture of hippocampal neurons in SREBP-1c knockout (KO) mice. During the passive avoidance test, SREBP-1c KO mice showed memory impairment. Based on Golgi staining, the dendritic complexity, length, and branch points were significantly decreased in the apical cornu ammonis (CA) 1, CA3, and dentate gyrus (DG) subregions of the hippocampi of SREBP-1c KO mice, compared with those of wild-type (WT) mice. Additionally, significant decreases in the dendritic diameters were detected in the CA3 and DG subregions, and spine density was also significantly decreased in the apical CA3 subregion of the hippocampi of KO mice, compared with that of WT mice. Alterations in the proportions of stubby and thin-shaped dendritic spines were observed in the apical subcompartments of CA1 and CA3 in the hippocampi of KO mice. Furthermore, the corresponding differential decreases in the levels of SREBP-1 expression in the hippocampal subregions (particularly, a significant decrease in the level in the CA3) were detected by immunofluorescence. This study suggests that the contributions of SREBP-1c to the structural plasticity of the mouse hippocampus may have underlain the behavioral alterations. These findings offer insights into the critical role of SREBP-1c in hippocampal functioning in mice.
\end{abstract}

Keywords: SREBP-1c; hippocampal neuron; dendritic complexity; structural plasticity; behavioral aberrations

\section{Introduction}

Alterations in neuronal structure and function have been implicated in the pathophysiology of various neurological disorders [1]. In the brain, the hippocampus is one of the few remaining regions capable of undergoing neuronal plasticity even during adulthood, 
rendering it especially susceptible to structural and functional alterations [2,3]. These hippocampal alterations further translate to abnormalities of emotions, learning, and memory [4]. These hippocampal abnormalities in volume [5,6], synaptic circuitry [7], and cytoarchitecture [8] have been reported in patients with neurological diseases, including schizophrenia. Rodent models of hippocampal lesions also demonstrate congruent pharmacological, anatomical, and behavioral phenotypes of schizophrenia [9].

Lipids are vital for brain function as they constitute the bulk of the brain and they function in cellular signaling, myelin generation, and neuroplasticity [10]. The brain is largely dependent on de novo lipid synthesis as the blood-brain barrier limits the exogenous lipid transport into the brain [11,12]. Sterol regulatory element-binding proteins (SREBPs) are considered the master regulators of lipid synthesis [13]. SREBPs are transcription factors, controlling both cholestero- and lipogenesis, via the activation of enzymatic cascades required for the synthesis of endogenous cholesterol, fatty acids, and triglycerides [14]. In mammals, three SREBP isoforms have been described, of which SREBP-1a and SREBP-1c are both produced from different transcription sites (exon 1a and exon 1c) of the same Srebf-1 gene [15], while SREBP-2 originates from the Srebf-2 gene [16]. SREBP-1c is the predominant isoform expressed in most tissues, including the white adipose tissue, liver, and brain. SREBP-1a is predominantly expressed in cellular proliferative tissues, such as the spleen and intestine [17], while SREBP-2 is ubiquitously expressed throughout the body at amounts approximately equal to the total of the SREBP-1a and 1c expression [18]. Although there is a commonality in their activities, SREBP-1c favors the control of fatty acid and triglyceride synthesis, while SREBP-2 mainly regulates cholesterol synthesis and SREBP-1a does not display any particular preference [13].

Previously, we found that mice lacking SREBP-1c demonstrate schizophrenia-like behavioral symptoms [19]. Furthermore, we found that novel genes (e.g., glucagon-like peptide 2 receptor (Glp2r), necdin (Ndn), and Erb-B2 receptor tyrosine kinase 4) were significantly altered in the hippocampus of SREBP-1c knockout $(\mathrm{KO})$ mice, compared with those in wild-type (WT) mice [20]. However, the mechanisms possibly underlying these abnormal behaviors and altered molecular expressions need further examination. Thus, we sought to investigate the potential changes in functional and structural neuroplasticity of the hippocampus of SREBP-1c KO mice, which may provide new insights into the role of SREBP-1c in the hippocampus and its potential relevance to the development of animal experimental systems for neurological disorders such as schizophrenia.

In this study, we first confirmed hippocampal function in SREBP-1c KO mice by measuring hippocampus-dependent learning and memory ability using the passive avoidance task. Subsequently, we investigated the structural neuroplasticity of the hippocampi of SREBP-1c KO mice by measuring various parameters of dendritic and spine morphology in the different subregions, including the cornu ammonis (CA) 1, CA3, and dentate gyrus (DG); we also characterized the different changes in the morphological parameters in the various subregions. Further, the levels of SREBP-1 expression in the various subregions of mice hippocampi were analyzed. Finally, the possible association between the alteration of structural plasticity and lack of SREBP-1c expression will be discussed.

\section{Results}

\subsection{SREBP-1c KO Mice Demonstrate Significantly Decreased Hippocampus-Dependent Memory Retention}

Previously, we observed that SREBP-1c KO mice had altered behaviors suggestive of the positive and negative symptoms of schizophrenia, but not its cognitive symptoms. To further assess cognitive symptoms, we used the passive avoidance task as a hippocampusdependent paradigm. During the training period, both WT and KO mice had short cross-over latencies before entering the dark compartment where they received a foot shock. Interestingly, during the testing period, memory retention was significantly reduced in KO mice, compared with WT mice. This was evidenced by the significantly shorter increase in the cross-over latency during the testing period (Figure 1). 


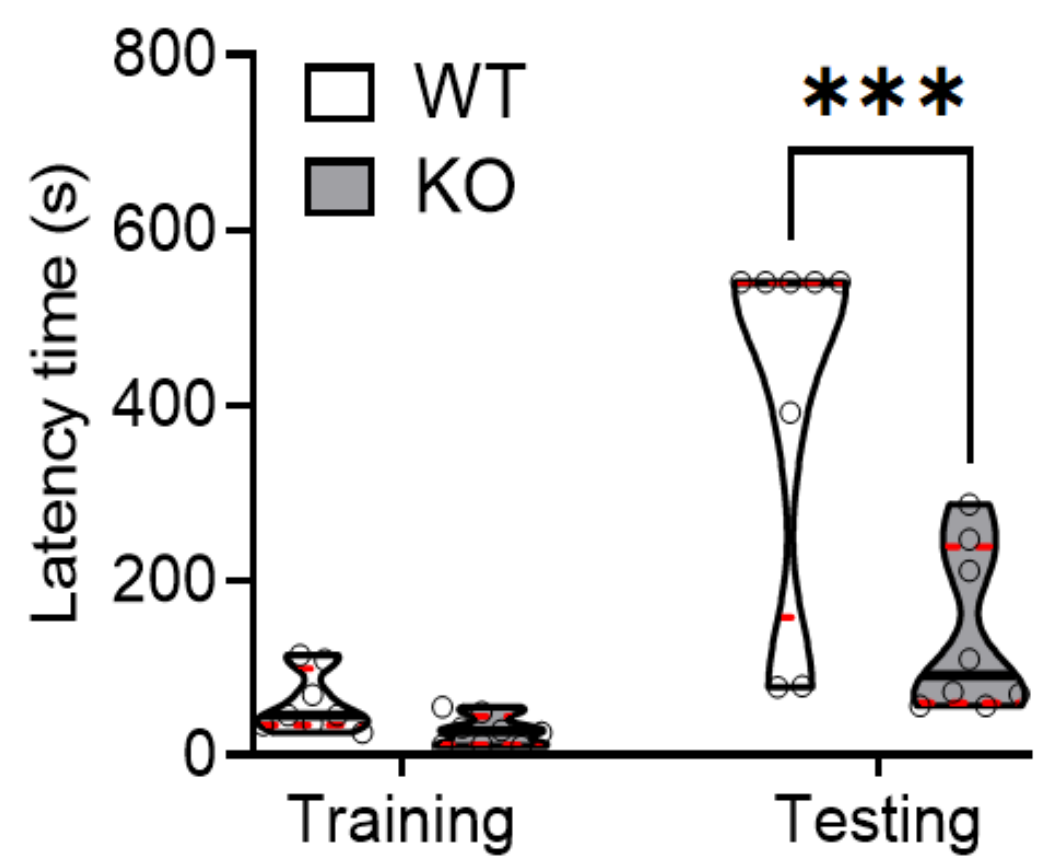

Figure 1. SREBP-1c deficiency significantly impairs learning and memory function in mice. Using the passive avoidance test, WT and SREBP-1c KO mice were trained using mild electrical foot shocks. Both groups were tested $24 \mathrm{~h}$ after training. Cross-over latency (s) was assessed to evaluate memory retention. SREBP-1c KO mice showed a significantly lesser increase in the cross-over latency before entering the dark room during testing than WT mice (WT: $406 \pm 208.77 \mathrm{~s}, \mathrm{KO}: 138.3 \pm 94.40 \mathrm{~s}, n=8$ per group; $\left.F_{\text {interaction }}(1,14)=10.17, p=0.0002\right)$. The upper and lower dashed red lines signify the upper and lower quartiles, respectively, and the median is represented by a solid black line within a violin plot. ${ }^{* *} p<0.001$ vs. WT. WT, wild-type littermate; KO, SREBP-1c KO group.

\subsection{SREBP-1c KO Mice Display Altered Dendritic Morphology in the Hippocampus}

Sholl analysis was used to quantify the dendritic complexity of the Golgi-stained neurons. The total number of dendritic intersections was recorded per $10 \mu \mathrm{m}$ incremental radial distance from the soma. Overall, SREBP-1c KO mice, compared with WT mice, had decreased dendritic complexity (Figure 2a). The complexity was significantly reduced in apical CA1, apical and basal CA3, and DG, but not in the basal subcompartment of CA1 (Figure 2b). Apical CA1 dendrites in SREBP-1c KO mice demonstrated significantly fewer intersections than WT mice at the Sholl radii of 130-150 $\mu \mathrm{m}$ from the soma (Figure 2b, upper left line graphs). The number of intersections of the CA3 dendrites in SREBP-1c KO mice, compared with those in WT mice, were significantly reduced in the apical subcompartment at the Sholl radii of 110-180 $\mu \mathrm{m}$ from the soma (Figure 2b, upper middle line graphs) and in the basal subcompartment at the Sholl radii of 110-140 $\mu \mathrm{m}$ from the soma (Figure $2 b$, lower right line graphs). The DG granule cell dendrites of $\mathrm{KO}$ mice also had significantly less intersections than those of WT mice at Sholl radii of 70-110 $\mu \mathrm{m}$ from the soma (Figure $2 b$, upper right line graphs). However, no significant differences between SREBP-1c KO and WT mice in the basal compartment of the CA1 subregion were observed (Figure 2b, lower left line graphs). Table 1 shows the results of the two-way ANOVA tests for the effects of the genotype and distance on dendritic arborization (mean no. of crossing dendrites) in each hippocampal subregion of WT and KO mice measured by Sholl analysis ( $n=40$ neurons/group). 
(a)
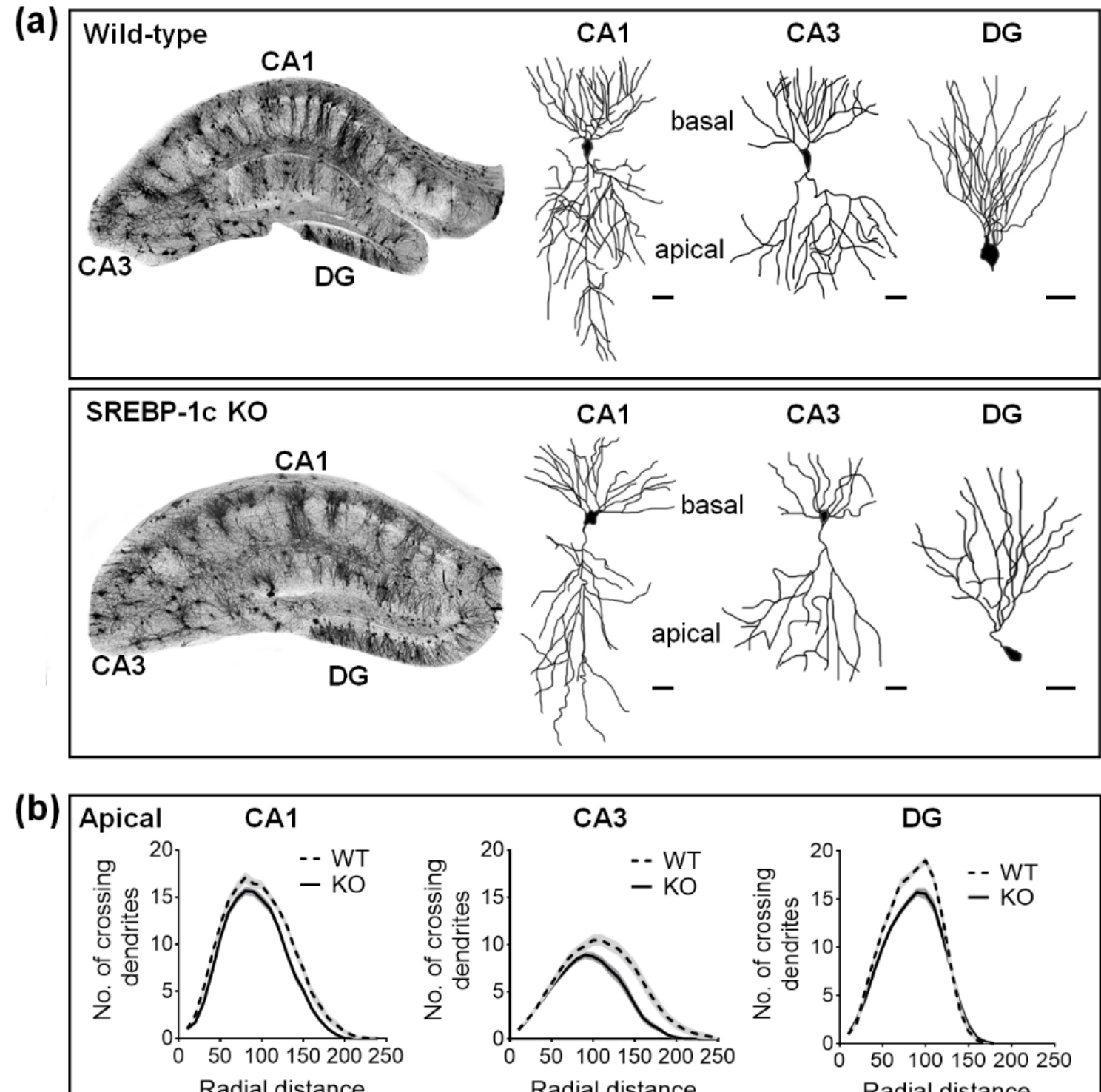

Radial distance from the soma $(\mu \mathrm{m})$
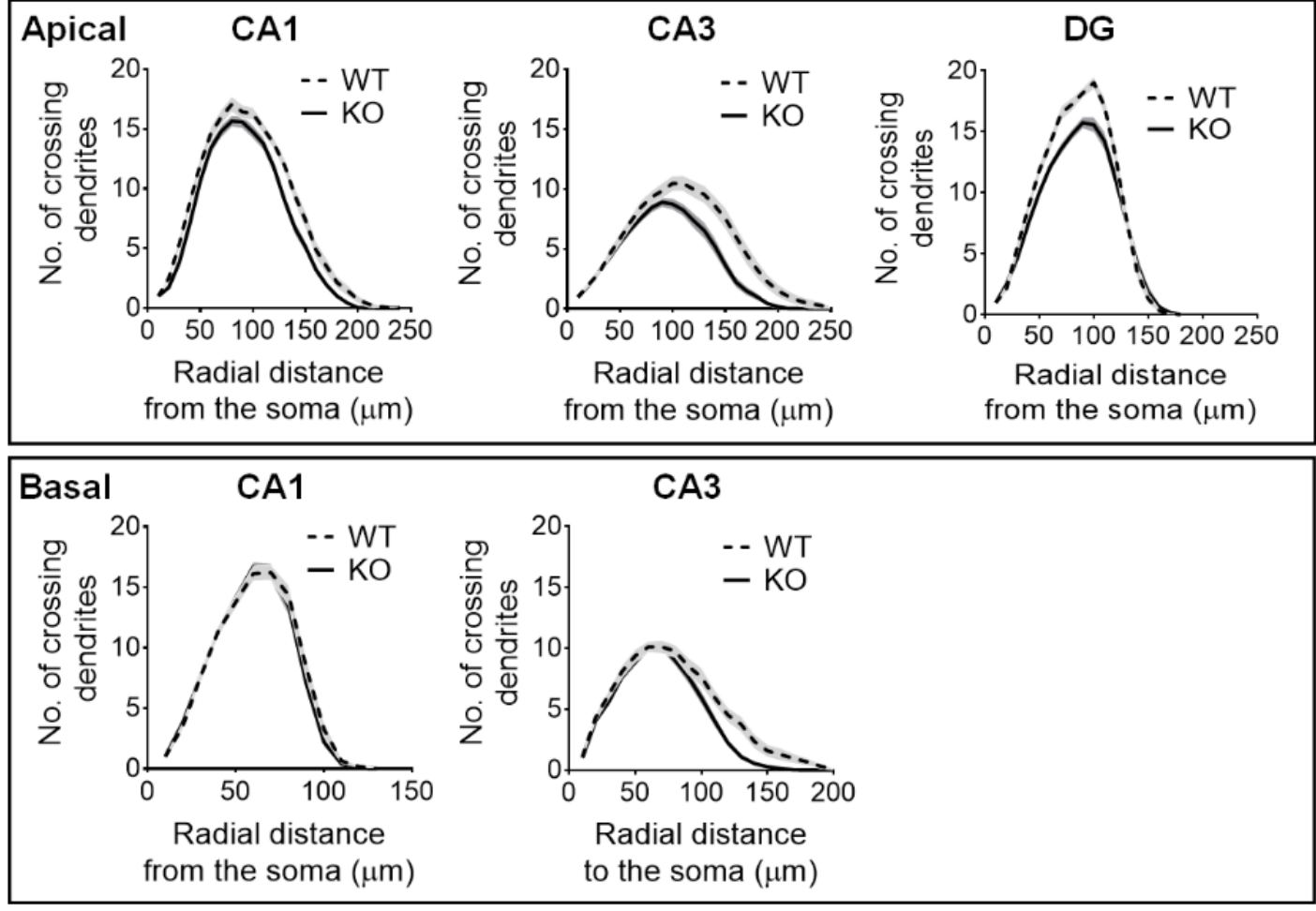

Figure 2. SREBP-1C KO mice display impaired dendritic complexity in the CA1, CA3, and DG subregions of the hippocampus. The figures show the representative images of the Golgi-stained hippocampus and subregional neurons in WT and SREBP-1c KO mice (a). The line graphs show the mean number of intersections per $10 \mu \mathrm{m}$ radial unit distance from the soma (0) for apical ((b); upper) and basal ((b); lower) dendrites. Data are expressed as means \pm standard errors (SEs) of 10 neurons of each subregion in each mouse ( $n=40$ dendrites/group). The scale bars in (a) represent $25 \mu \mathrm{m}$. CA, cornu ammonis; DG, dentate gyrus; WT, wild-type littermate; KO, SREBP-1c KO group. 
Table 1. Results of two-way ANOVA tests for the effects of the genotype and distance on dendritic arborization (mean no. of crossing dendrites) in each hippocampal subregion of WT and KO mice measured by Sholl analysis ( $n=40$ neurons/group).

\begin{tabular}{|c|c|c|c|}
\hline & Sholl Radii Distance $(\mu \mathrm{m})^{1}$ & Šidăk's Post Hoc Test per Sholl Radii Distance & Two-Way ANOVA \\
\hline CA1 & $130,140,150$ & $p=0.0001, p=0.0007, p=0.0121$ & $F_{\text {interaction }}(23,1794)=1.741, p=0.0161$ \\
\hline basal & n.s. & n.s. & $F_{\text {interaction }}(12,936)=0.8516, p=0.5969$ \\
\hline $\begin{array}{l}\text { CA3 } \\
\text { apical }\end{array}$ & $110,120,130,140,150,160,170,180$ & $\begin{array}{l}p=0.0371, p=0.0046, p=0.0004, p<0.0001 \\
p<0.0001, p<0.0001, p=0.0004, p=0.0257\end{array}$ & $\mathrm{~F}_{\text {interaction }}(24,1872)=3.985, p<0.0001$ \\
\hline basal & $110,120,130,140$ & $p=0.0243, p=0.0023, p=0.0002, p=0.0490$ & $F_{\text {interaction }}(19,1482)=2.098, p=0.0037$ \\
\hline DG & $70,80,90,100,110$ & $p=0.0014, p=0.0149, p=0.0189, p<0.0001, p=0.0025$ & $F_{\text {interaction }}(17,1326)=4.031, p<0.0001$ \\
\hline
\end{tabular}

${ }^{1}$ At different radial distances from the neuronal soma, the number of dendritic intersections was quantified in each hippocampal subregion, using Sholl analysis. Radial distances with significantly reduced mean numbers of crossing dendrites between WT and KO. Abbreviations: ANOVA, analysis of variance; CA1, cornu ammonis 1; DG, dentate gyrus; KO, SREBP-1c knockout; WT, wild-type; n.s., not significant.

The total dendritic length was also significantly reduced in the hippocampi of SREBP1c KO mice, compared with those of WT mice (Figure 3a,b). Deficiencies were observed in the apical CA1 (Figure 3a, left violin plots), apical CA3 (Figure 3a, middle violin plots), DG subregions (Figure 3a, right violin plots), and basal CA3 (Figure 3b, right violin plots), but not in the basal subcompartment of CA1 (Figure 3b, left violin plots).
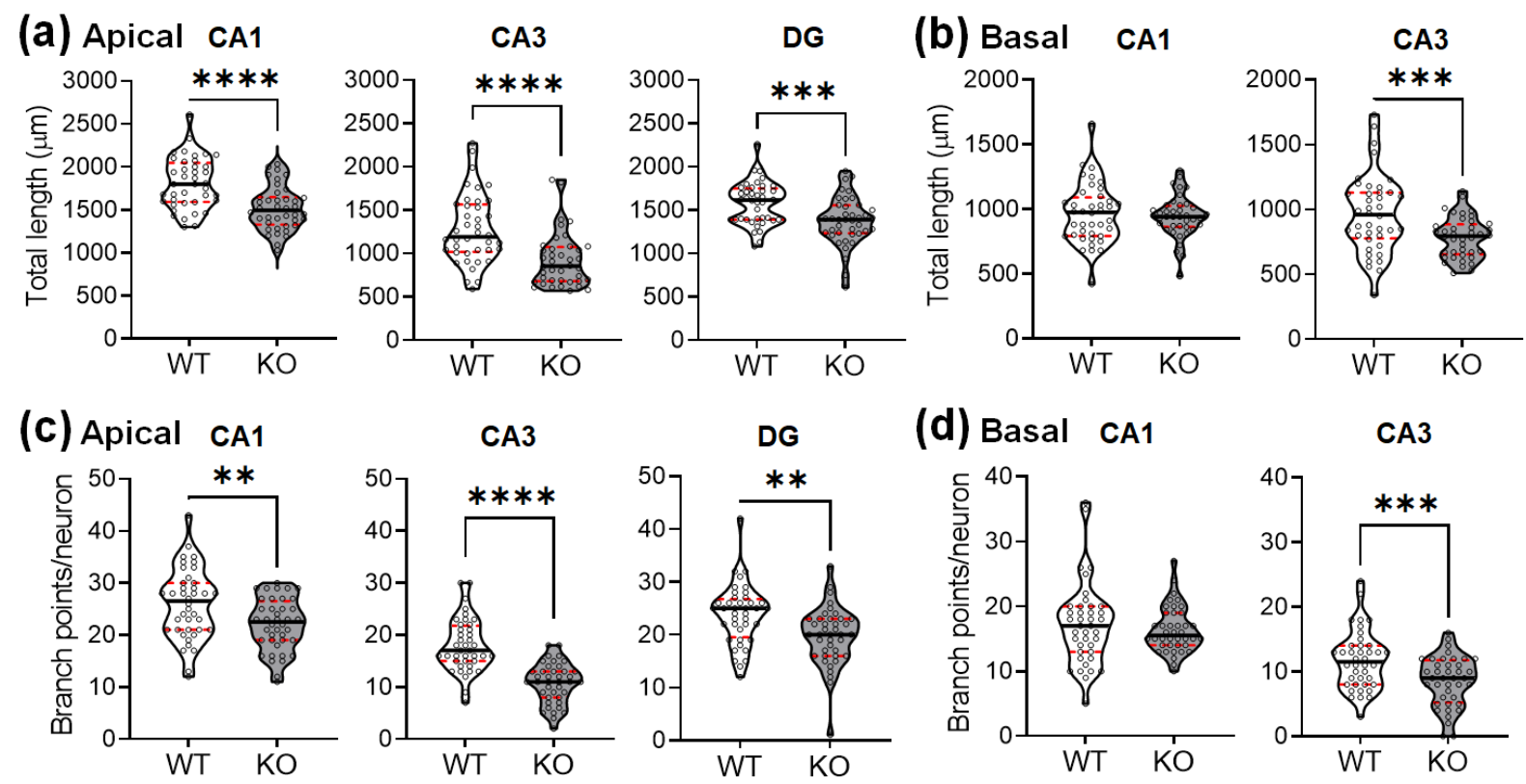

(d) Basal CA1
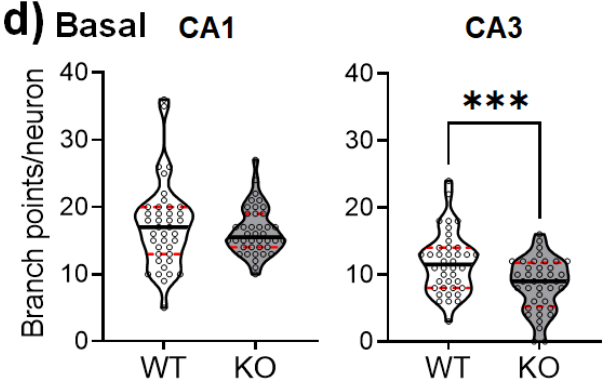

(e) Apical CA1
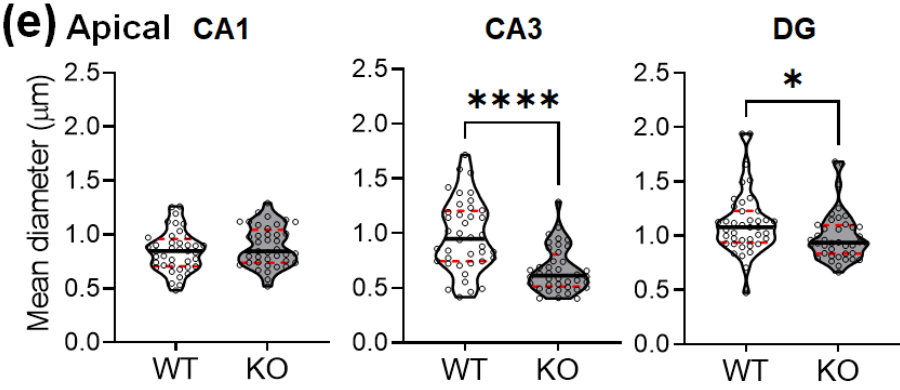

(f) Basal CA1

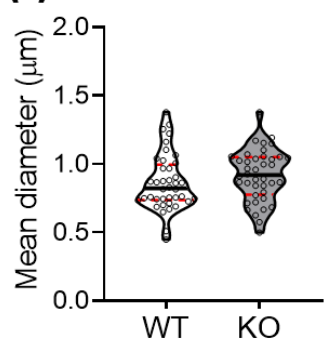

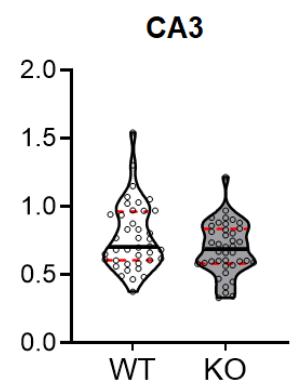

Figure 3. SREBP-1C KO mice show decreases in the length, number of branch points, and diameter of the dendrites in the hippocampus. Violin plots show the total length $(\mathbf{a}, \mathbf{b})$, number of branch points $(\mathbf{c}, \mathbf{d})$, and mean diameter $(\mathbf{e}, \mathbf{f})$ of the dendrites in each subregion (CA1, CA3, and DG). The upper and lower dashed red lines signify the upper and lower quartiles, respectively, and the median is represented by a solid black line within the violin plots. ${ }^{*} p<0.05,{ }^{* *} p<0.01$, ${ }^{* * *} p<0.001$, and ${ }^{* * * *} p<0.0001$ vs. WT ( $n=40$ dendrites/group). CA, cornu ammonis; DG, dentate gyrus; WT, wild-type littermate; KO, SREBP-1c KO group. 
A corresponding decrease in the dendritic branching points was also observed in the hippocampi of KO mice compared with those of WT mice (Figure 3c,d). The branch points per neuron were reduced in the apical CA1 (Figure 3c, left violin plots), apical CA3 (Figure 3c, middle violin plots), DG subregions (Figure 3c, right violin plots), and basal CA3 (Figure 3d, right violin plots), but not in the basal subcompartment of CA1 (Figure 3d, left violin plots).

The Golgi-stained neurons were also examined for variations in the dendritic thickness in $\mathrm{WT}$ and $\mathrm{KO}$ mice (Figure 3e,f). The dendritic diameters were significantly reduced in the apical CA3 (Figure 3e, middle violin plots) and DG subregions (Figure 3e, right violin plots) of KO mice, but not in the other areas (CA1 apical: Figure 3e, left violin plots; CA1 basal: Figure 3f, left violin plots; CA3 basal: Figure 3f, right violin plots).

Table 2 shows the results of Student's $t$-tests for total dendritic lengths, branch points, and thickness of the hippocampal neurons in each subregion between WT and KO mice ( $n=40$ neurons/group).

Table 2. Results of Student's $t$-tests for total dendritic lengths, branch points, and thickness of the hippocampal neurons in each subregion between WT and KO mice ( $n=40$ neurons/group).

\begin{tabular}{|c|c|c|c|}
\hline & WT & KO & Student's $t$-Test \\
\hline \multicolumn{4}{|c|}{ Total dendritic length $(\mu \mathrm{m})$} \\
\hline CA1 apical & $1811.3 \pm 296.7$ & $1516 \pm 251.8$ & $\mathrm{t}(78)=4.794, p<0.0001$ \\
\hline basal & $964.3 \pm 229.5$ & $940.8 \pm 160.4$ & $\mathrm{t}(78)=0.531, p=0.5971$ \\
\hline CA3 apical & $1281 \pm 398$ & $924 \pm 308.2$ & $\mathrm{t}(78)=4.482, p<0.0001$ \\
\hline basal & $967.5 \pm 301.2$ & $783 \pm 156.1$ & $\mathrm{t}(78)=3.440, p=0.0009$ \\
\hline DG & $1576 \pm 245.1$ & $1374 \pm 278.5$ & $\mathrm{t}(78)=3.448, p=0.0009$ \\
\hline \multicolumn{4}{|c|}{ Dendritic branch points } \\
\hline CA1 apical & $25.9 \pm 6.7$ & $22.0 \pm 5.0$ & $\mathrm{t}(78)=2.956, p=0.0041$ \\
\hline basal & $17.3 \pm 6.3$ & $16.4 \pm 3.6$ & $\mathrm{t}(78)=0.719, p=0.4741$ \\
\hline CA3 apical & $18.1 \pm 5.1$ & $10.6 \pm 3.9$ & $\mathrm{t}(78)=7.201, p<0.0001$ \\
\hline basal & $11.8 \pm 4.5$ & $8.5 \pm 3.9$ & $\mathrm{t}(78)=3.469, p=0.0009$ \\
\hline DG & $28.3 \pm 5.7$ & $19.7 \pm 5.5$ & $\mathrm{t}(78)=3.282, p=0.0015$ \\
\hline \multicolumn{4}{|c|}{ Dendritic thickness $(\mu \mathrm{m})$} \\
\hline CA1 apical & $0.845 \pm 0.190$ & $0.890 \pm 0.185$ & $\mathrm{t}(78)=1.031, p=0.3056$ \\
\hline basal & $0.864 \pm 0.206$ & $0.916 \pm 0.189$ & $\mathrm{t}(78)=1.168, p=0.2462$ \\
\hline CA3 apical & $0.976 \pm 0.325$ & $0.664 \pm 0.202$ & $\mathrm{t}(78)=5.162, p<0.0001$ \\
\hline basal & $0.775 \pm 0.244$ & $0.689 \pm 0.190$ & $\mathrm{t}(78)=1.760, p=0.0823$ \\
\hline DG & $1.117 \pm 0.291$ & $0.994 \pm 0.228$ & $\mathrm{t}(78)=2.013, p=0.0387$ \\
\hline
\end{tabular}

The data are expressed as the means \pm standard deviation. Abbreviations: CA, cornu ammonis; DG, dentate gyrus; KO, SREBP-1c knockout; WT, wild-type.

\subsection{SREBP-1c KO Mice Show Altered Dendritic Spine Density and Morphology in the Hippocampus}

The Golgi-stained neurons were magnified and analyzed for possible changes in the dendritic spines. The mice lacking SREBP-1c had significant alterations in spine density and morphology only in the apical subcompartment of the CA1 and CA3 subregions (Figure 4). The spine densities (number of spines per $10 \mu \mathrm{m}$ ) were not altered in the apical CA1 (Figure 4b, left violin plots), DG (Figure 4b, right violin plots), basal CA1 (Figure 4c, left violin plots), and basal CA3 (Figure 4c, right violin plots), although they significantly decreased in the apical CA3 subregions (Figure $4 b$, middle violin plots). Table 3 shows the results of Student's $t$-tests for the dendritic spine density (per dendritic segments of $10 \mu \mathrm{m}$ ) of the hippocampal neurons in each subregion between WT and KO mice $(n=40$ dendritic segments/group). 
(a)
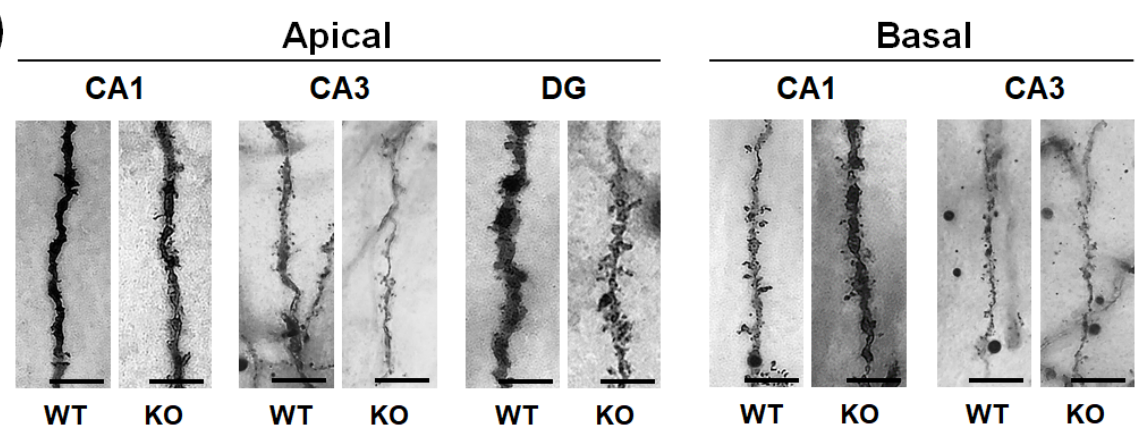

(b) Apical CA1
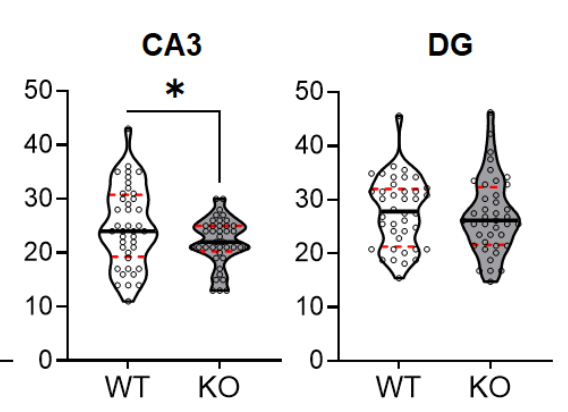

(c) Basal CA1

CA3
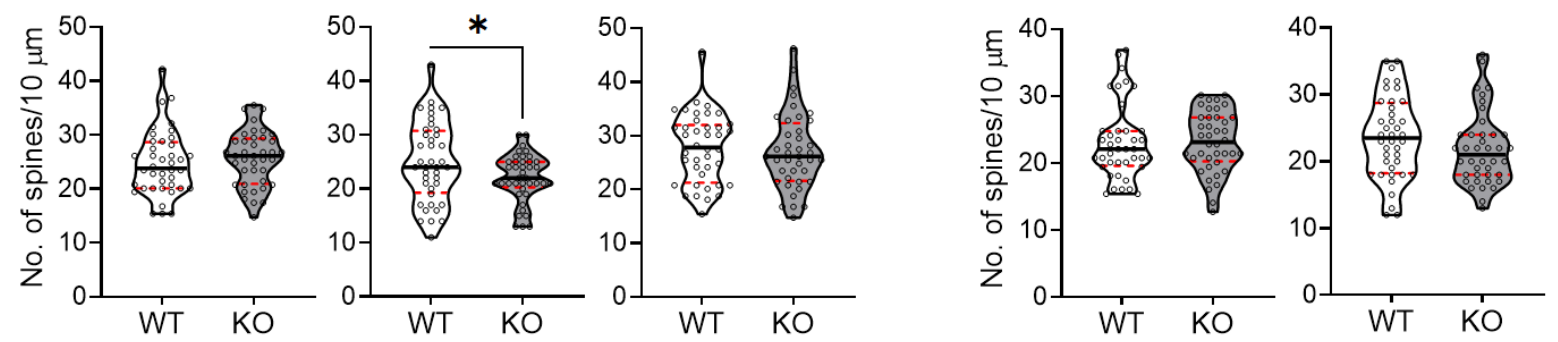

\section{(d) Apical}

CA1
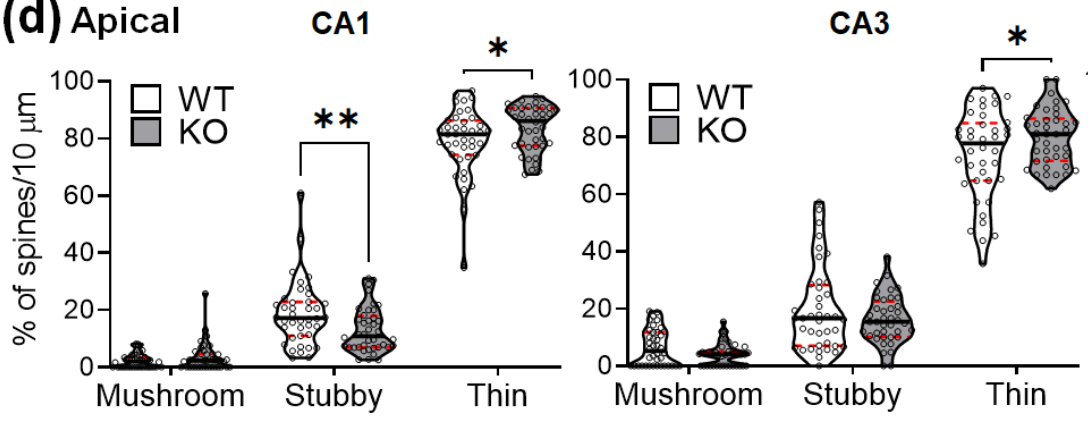

DG
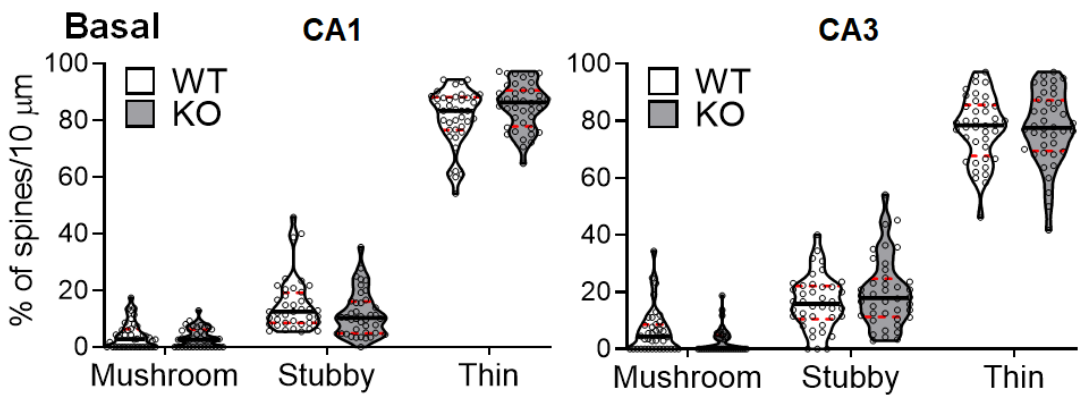

Figure 4. SREBP-1c KO mice show altered dendritic spine density and morphological proportions in the hippocampus. Representative images from each cohort show dendritic segments and their spines along Golgi-impregnated neurons (a). Violin plots show the total number of spines in each subregion (CA1, CA3, and DG) (b,c). Violin plots show the proportions of the spines categorized by morphology in each subregion (CA1, CA3, and DG) (d). Upper and lower dashed red lines signify the upper and lower quartiles, respectively, and the median is represented by a solid black line within a violin plot. ${ }^{*} p<0.05,{ }^{* *} p<0.01$ vs. WT ( $n=40$ dendritic segment/group). The scale bars in the dendritic images represent $5 \mu \mathrm{m}$. CA, cornu ammonis; DG, dentate gyrus; WT, wild-type littermate; KO, SREBP-1c KO group. 
Table 3. Results of Student's $t$-tests for the dendritic spine density (per dendritic segments of 10 $\mu \mathrm{m})$ of the hippocampal neurons in each subregion between WT and KO mice $(n=40$ dendritic segments/group).

\begin{tabular}{cccc}
\hline & WT & KO & Student's $t$-Test \\
\hline CA1 apical & $24.8 \pm 6.0$ & $25.7 \pm 5.1$ & $\mathrm{t}(78)=0.7302, p=0.4675$ \\
basal & $23.1 \pm 5.7$ & $23.2 \pm 4.5$ & $\mathrm{t}(78)=0.0146, p=0.9884$ \\
CA3 apical & $24.9 \pm 7.5$ & $22.0 \pm 4.4$ & $\mathrm{t}(78)=2.108, p=0.0382$ \\
basal & $23.6 \pm 6.2$ & $21.9 \pm 5.5$ & $\mathrm{t}(78)=1.362, p=0.1770$ \\
DG & $27.7 \pm 6.5$ & $27.1 \pm 7.1$ & $\mathrm{t}(78)=0.4203, p=0.6754$ \\
\hline
\end{tabular}

The data are expressed as the means \pm standard deviation. Abbreviations: CA, cornu ammonis; DG, dentate gyrus; KO, SREBP-1c knockout; WT, wild-type.

Changes in the proportions of different dendritic spine morphologies were observed in the apical CA1 and apical CA3 subregions. Stubby spines were significantly reduced in the apical CA1 subregion (Figure 4d, upper left violin plots), but not in the other areas. In contrast, the thin spines were significantly increased in the apical CA1 (Figure 4d, upper left violin plots) and apical CA3 subregions (Figure 4d, upper middle violin plots), but not in the other subregions. No significant changes in the proportion of mushroom-shaped spines were observed. Table 4 shows the results of two-way ANOVA tests for the effects of the genotype and spine morphology on the proportion of dendritic spines in each hippocampal subregion of WT and KO mice ( $n=40$ dendritic segments $(10 \mu \mathrm{m}) /$ group).

Table 4. Results of two-way ANOVA tests for the effects of genotype and spine morphology on the proportion of dendritic spines in each hippocampal subregion of WT and KO mice $(n=40$ dendritic segments $(10 \mu \mathrm{m}) /$ group $)$.

\begin{tabular}{|c|c|c|c|c|}
\hline & Mushroom Spines (\%) & Stubby Spines (\%) & Thin Spines (\%) & Two-Way ANOVA \\
\hline \multicolumn{5}{|c|}{ CA1 apical } \\
\hline $\begin{array}{l}\text { WT } \\
\text { KO }\end{array}$ & $\begin{array}{c}2.2 \pm 2.6 \\
3.4 \pm 4.9 \\
p=0.9026^{1}\end{array}$ & $\begin{array}{c}18.7 \pm 11.2 \\
13.0 \pm 7.8 \\
p=0.0082^{1}\end{array}$ & $\begin{array}{c}79.1 \pm 11.8 \\
83.6 \pm 7.9 \\
p=0.0487^{1}\end{array}$ & $\mathrm{~F}_{\text {interaction }}(2,156)=5.126, p=0.0070$ \\
\hline \multicolumn{5}{|c|}{ CA1 basal } \\
\hline $\begin{array}{l}\text { WT } \\
\text { KO }\end{array}$ & $\begin{array}{c}4.0 \pm 4.7 \\
3.3 \pm 3.2 \\
p=0.9630^{1}\end{array}$ & $\begin{array}{c}14.9 \pm 9.3 \\
11.7 \pm 7.9 \\
p=0.1753^{1}\end{array}$ & $\begin{array}{c}81.0 \pm 10 \\
84.9 \pm 8.2 \\
p=0.0647^{1}\end{array}$ & $F_{\text {interaction }}(2,156)=3.003, p=0.0525$ \\
\hline \multicolumn{5}{|c|}{ CA3 apical } \\
\hline $\begin{array}{l}\text { WT } \\
\text { KO }\end{array}$ & $\begin{array}{c}6.4 \pm 6.3 \\
3.9 \pm 3.9 \\
p=0.6465^{1}\end{array}$ & $\begin{array}{c}19.7 \pm 14.8 \\
16.2 \pm 8.4 \\
p=0.3666^{1}\end{array}$ & $\begin{array}{c}73.8 \pm 15.8 \\
79.9 \pm 9.8 \\
p=0.0357^{1}\end{array}$ & $\mathrm{~F}_{\text {interaction }}(2,156)=3.231, p=0.0422$ \\
\hline \multicolumn{5}{|c|}{ CA3 basal } \\
\hline $\begin{array}{l}\text { WT } \\
\text { KO }\end{array}$ & $\begin{array}{c}6.3 \pm 7.8 \\
2.7 \pm 4.3 \\
p=0.3040^{1}\end{array}$ & $\begin{array}{c}16.3 \pm 9.4 \\
19.7 \pm 12 \\
p=0.3488^{1}\end{array}$ & $\begin{array}{l}77.4 \pm 11.5 \\
77.6 \pm 12.8 \\
p=0.9997^{1}\end{array}$ & $\mathrm{~F}_{\text {interaction }}(2,156)=1.599, p=0.2054$ \\
\hline \multicolumn{5}{|c|}{ DG } \\
\hline $\begin{array}{l}\text { WT } \\
\text { KO }\end{array}$ & $\begin{array}{c}4.2 \pm 3.9 \\
5.1 \pm 5.2 \\
p=0.9285^{1}\end{array}$ & $\begin{array}{c}12.3 \pm 6.7 \\
9.9 \pm 6.8 \\
p=0.3283^{1}\end{array}$ & $\begin{array}{c}83.4 \pm 8.3 \\
84.9 \pm 8.7 \\
p=0.6861^{1}\end{array}$ & $\mathrm{~F}_{\text {interaction }}(2,156)=1.224, p=0.2970$ \\
\hline
\end{tabular}

\footnotetext{
${ }^{1}$ Šidăk's post hoc test. The data are expressed as the means \pm standard deviation. Abbreviations: ANOVA, analysis of variance; CA, cornu
} ammonis; DG, dentate gyrus; KO, SREBP-1c knockout; WT, wild-type.

\subsection{The CA3 Subregion of SREBP-1c KO Mice Shows Significantly Greater Decreases in} Dendritic and Spine Morphological Parameters Compared to Those of Other Subregions

To determine if there are subregion-specific differences in the degree of morphological alterations observed, the log2 fold changes in WT mice were computed for each structural parameter. Of the different subregions, the CA3 subregion had the greatest decreases 
in dendritic length, number of branch points, diameter, and spines compared with the CA1 subregion and DG subregion (Figure 5a, bar graphs). Table 5 shows the results of two-way ANOVA tests for the effects of the hippocampal subregion and morphological parameters on $\log 2$ fold changes in KO mice relative to WT mice. Table 6 shows the summary of P-values from Šidăk's post hoc analyses for the comparison of the different hippocampal subregions in Table 5. To better visualize the subregion-specific differences in the morphological changes, the same set of data is expressed as a heatmap in Figure 5b.

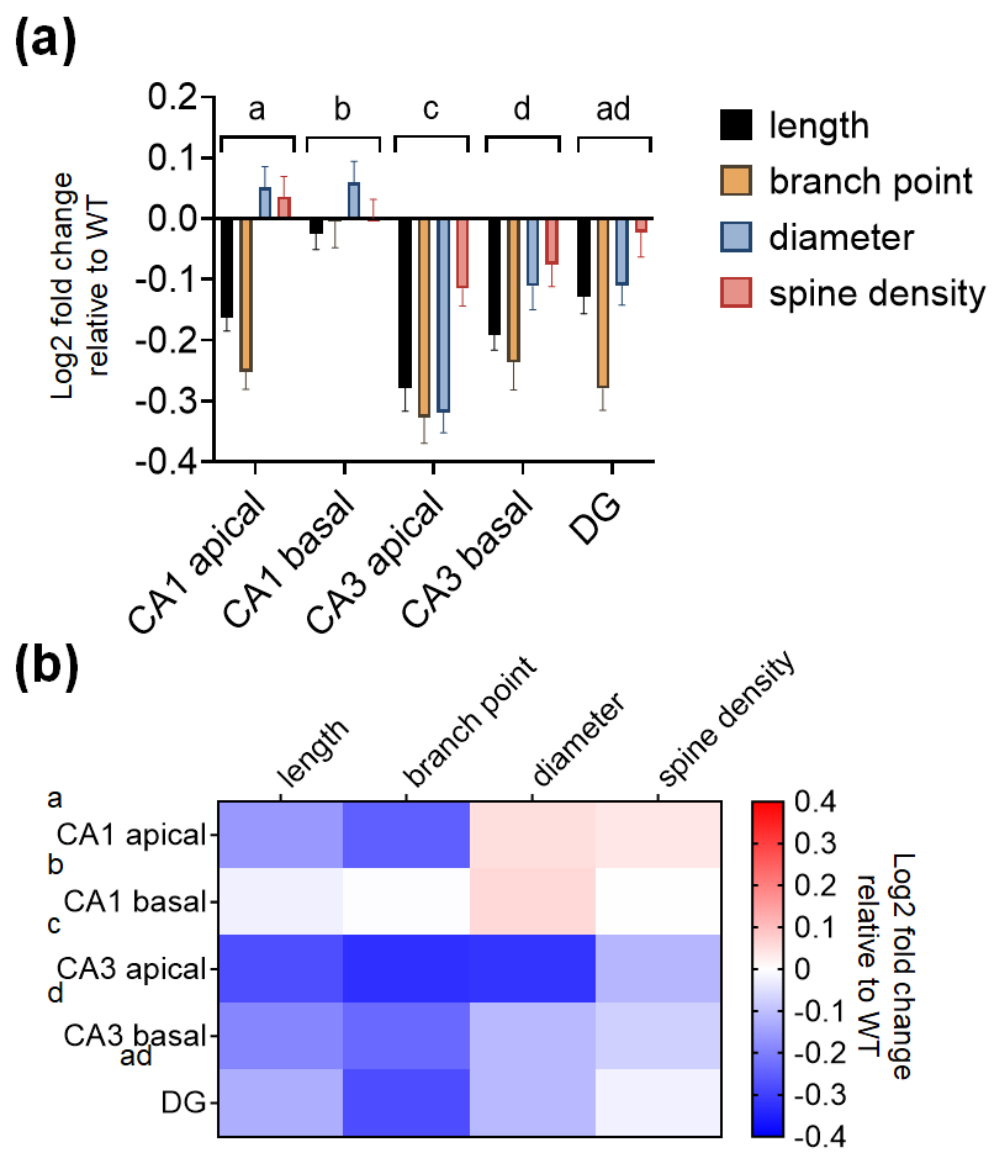

Figure 5. SREBP-1c KO mice show greater morphological alterations in the CA3 than in the other subregions of the hippocampus. Fold changes in dendritic and spine morphological characteristics in WT mice are represented as bar graphs (a) and heatmaps (b) to better visualize the degree of differences between the different hippocampal subregions (CA1, CA3, and DG). Data are expressed as means \pm SEs, and different letters, "a," " $b$," "c," and " $d$," indicate statistically significant differences between the subregions at $p<0.05$ ( $n=40$ neuron or dendrites/group). Bars with no common letters are significantly different $(p<0.05)$. CA, cornu ammonis; DG, dentate gyrus; WT, wild-type littermate group. 
Table 5. Results of two-way ANOVA tests for the effects of the hippocampal subregion and morphological parameters on $\log 2$ fold changes in KO mice relative to WT mice.

\begin{tabular}{cccccc}
\hline & Dendritic Length & $\begin{array}{c}\text { Dendritic Branch } \\
\text { Point }\end{array}$ & $\begin{array}{c}\text { Dendritic } \\
\text { Diameter }\end{array}$ & Spine Density & Two-Way ANOVA \\
\hline CA1 apical & $-0.16 \pm 0.022$ & $-0.25 \pm 0.029$ & $0.051 \pm 0.035$ & $0.037 \pm 0.032$ & \\
basal & $-0.02 \pm 0.026$ & $-0.004 \pm 0.043$ & $0.06 \pm 0.035$ & $0.0007 \pm 0.031$ & $\mathrm{Fi}_{\text {nteraction }}(12,780)$ \\
CA3 apical & $-0.28 \pm 0.038$ & $-0.33 \pm 0.042$ & $-0.32 \pm 0.033$ & $-0.12 \pm 0.028$ & $=3.718, p<0.0001$ \\
basal & $-0.19 \pm 0.026$ & $-0.24 \pm 0.045$ & $-0.11 \pm 0.039$ & $-0.08 \pm 0.037$ & $-0.02 \pm 0.04$ \\
DG & $-0.13 \pm 0.028$ & $-0.28 \pm 0.035$ & $-0.11 \pm 0.032$ & -0.032 \\
\hline
\end{tabular}

The data are expressed as the means \pm standard deviation. Abbreviations: ANOVA, analysis of variance; CA, cornu ammonis; DG, dentate gyrus; KO, SREBP-1c knockout; WT, wild-type.

Table 6. Summary of the P-values from Šidăk's post hoc analyses for the comparison of the different hippocampal subregions in Table 5.

\begin{tabular}{|c|c|c|c|c|c|}
\hline & CA1 Apical & CA1 Basal & CA3 Apical & CA3 Basal & $\overline{\mathrm{DG}}$ \\
\hline CA1 apical & & 0.0024 & $<0.0001$ & 0.0330 & 0.2481 \\
\hline CA1 basal & & & $<0.0001$ & $<0.0001$ & $<0.0001$ \\
\hline CA3 apical & & & & 0.0001 & $<0.0001$ \\
\hline CA3 basal & & & & & 0.9978 \\
\hline DG & & & & & \\
\hline
\end{tabular}

Abbreviations: CA, cornu ammonis; DG, dentate gyrus.

2.5. SREBP-1c KO Mice Show Significantly Reduced SREBP-1 Protein Expression in the CA3 Subregion of the Hippocampus

To evaluate the protein expression of SREBP-1 in the hippocampus, the sections were subjected to immunofluorescence staining, and the relative immunoreactive intensities were analyzed using ImageJ software (National Institutes of Health, Bethesda, MD, USA). The SREBP-1 protein was differentially expressed in the subregions of the hippocampi of WT and KO mice; the expressions were most intense in CA3, followed by CA1 and DG (Figure 6a,b). The relative intensities of SREBP-1 expression in the CA1 and DG subregions did not substantially differ in KO and WT mice. However, a significant decrease in SREBP-1 expression was detected in the CA3 subregion compared with that of WT mice of $\mathrm{KO}$ mice (Figure $6 \mathrm{~b}$, violin plots). Table 7 shows the results of two-way ANOVA tests for the effects of the genotype and hippocampal subregion on the relative immunoreactivity for SREBP-1 in WT and $\mathrm{KO}$ mice ( $n=5$ hippocampi/group). 

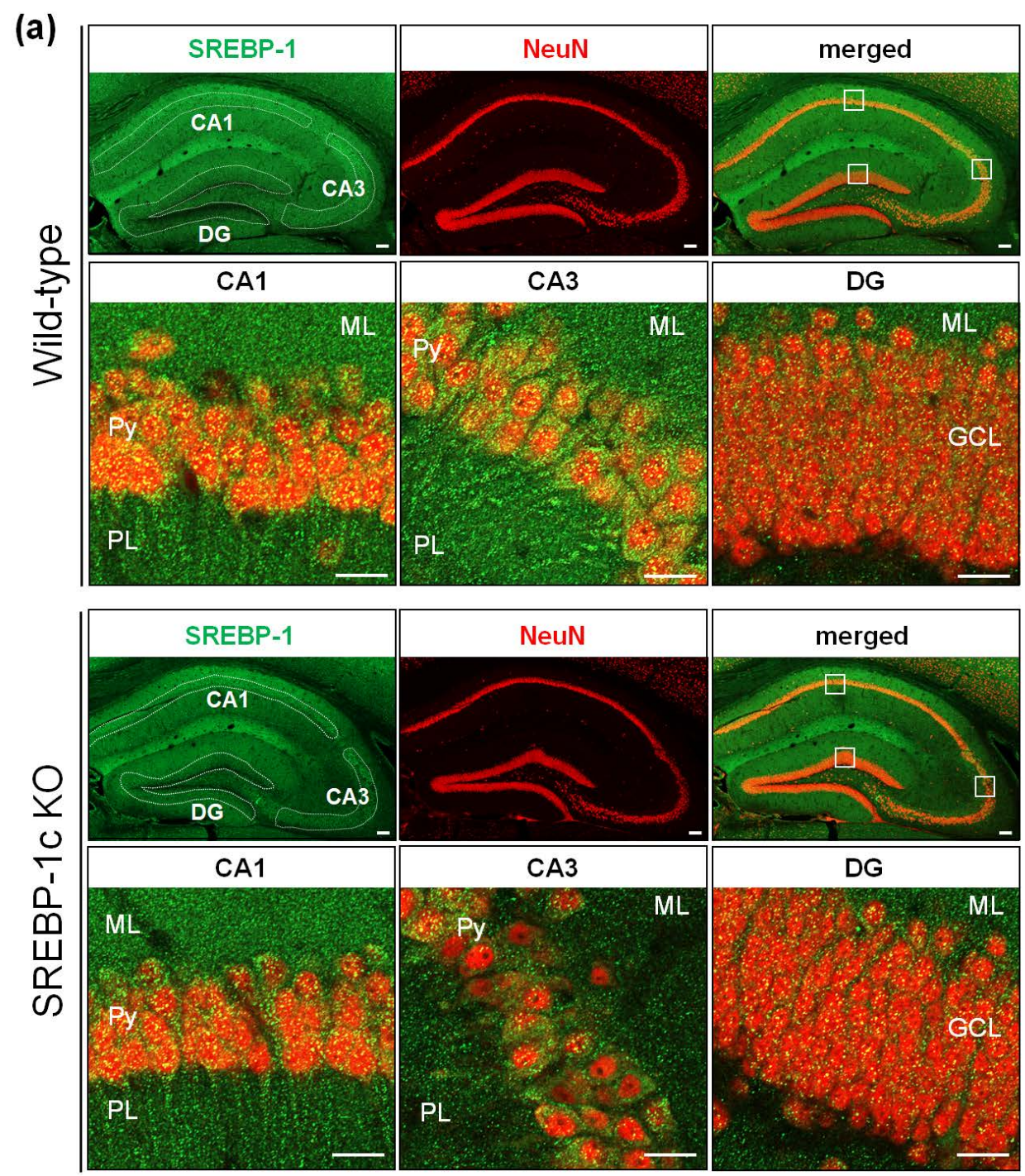

(b)

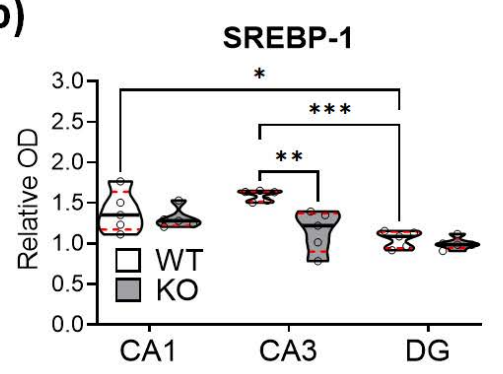

Figure 6. SREBP-1c KO mice show different levels of SREBP-1 protein expressions in each subregion of the hippocampus. Representative immunofluorescence images from each group show expressions of SREBP-1 (green) and NeuN (red)—a neuron-specific marker - in the various hippocampal subregions (CA1, CA3, and DG) (a). KO mice showed relatively lesser levels of SREBP-1 expression in all subregions, especially in the CA3 subregion; SREBP-1 was mainly expressed in the pyramidal and granular cell layers of the CA and DG subregions, respectively. Violin plots show the relative intensities of SREBP-1 expression in the pyramidal cell layers (CA1 and CA3) and granular cell layer (DG) in each of the hippocampal subregions (CA1, CA3, and DG) of WT and KO mice (b). Upper and lower dashed red lines represent the upper and lower quartiles, respectively, and the median is represented by a solid black line within a violin plot. ${ }^{*} p<0.05,{ }^{* *} p<0.01$, *** $p<0.001$ vs. WT ( $n=5$ animals/group). The scale bars represent 100 and $20 \mu \mathrm{m}$ in the hippocampal and subregion images, respectively. CA, cornu ammonis; DG, dentate gyrus; GCL, granular cell layer; ML, molecular layer; PL, polymorphic cell layer; Py, pyramidal cell layer; SREBP, sterol regulatory element-binding protein; NeuN, neuronal nuclei; WT, wild-type littermate; KO, SREBP-1c KO group. 
Table 7. Results of two-way ANOVA tests for the effects of the genotype and hippocampal subregion on the relative immunoreactivity for SREBP-1 in WT and KO mice ( $n=5$ hippocampi/group).

\begin{tabular}{ccccc}
\hline & WT & KO & Šidăk's Post Hoc Test & Two-Way ANOVA \\
\hline CA1 & $1.40 \pm 0.25^{1}$ & $1.31 \pm 0.13^{1}$ & $p=0.8182$ & Genotype: $\mathrm{F}(1,8)=6.392, p=0.0354$ \\
CA3 & $1.59 \pm 0.07^{1}$ & $1.15 \pm 0.25^{1}$ & $p=0.001$ & Subregion: $\mathrm{F}(2,16)=18.86, p<0.0001$ \\
DG & $1.05 \pm 0.10^{1}$ & $1 \pm 0.08^{1}$ & $p=0.9429$ & Interaction: $\mathrm{F}(2,16)=5.725, p=0.0133$ \\
\hline
\end{tabular}

${ }^{1}$ Relative optical density. The data are expressed as the means \pm standard deviation. Abbreviations: ANOVA, analysis of variance; CA, cornu ammonis; DG, dentate gyrus; KO, SREBP-1c knockout; WT, wild-type.

\section{Discussion}

We previously reported schizophrenia-like behavior and altered hippocampal gene expressions in SREBP-1c-deficient mice. In the present study, we expand on these findings by reporting congruent alterations in hippocampal micromorphometry and the function of SREBP-1c-deficient mice, compared with WT mice. Hippocampal function was measured using the passive avoidance task, while neuronal dendritic micromorphometry was analyzed in the tracings of Golgi-impregnated hippocampal neurons.

First, we identified a general impairment in the hippocampal function of SREBP-1c $\mathrm{KO}$ mice. We confirmed the deficiency in functional neuroplasticity related to poor learning and memory retention in $\mathrm{KO}$ mice using the passive avoidance task. This finding adds to the outcomes of our previous study, which found abnormal behavioral phenotypes resembling positive (hyperlocomotion) and negative (depression, aggression, and social deficit) schizophrenia-like behaviors [19]. Here, we demonstrated the cognitive aspect of schizophrenia-like behavior in SREBP-1c KO mice, which is reported to occur in $80 \%$ of the clinical cases and considered a main symptom of schizophrenia [21].

Proper dendritic morphology is essential for normal brain networking and functions, and morphological changes have been implicated in the development and symptoms of various psychiatric disorders, including schizophrenia [22]. In patients with schizophrenia, reductions in dendritic field size, dendritic length, and complexity in cortical or prefrontal cortical neurons have been demonstrated $[7,23]$. Several crucial molecules, including guanine deaminase cypin [24], Rho GTPases [25], and glutamate receptor-interacting protein [26], have been suggested to be involved in the mechanisms underlying dendritic branching; however, their specific associations with psychiatric disorders have not been established. In the current study, we observed the impairment of dendritic morphology related to decreased dendritic complexity, length, branch point, and diameter in $\mathrm{KO}$ mice. SREBPs are important regulators of lipid metabolism in the central nervous system, and SREBP-1c plays a key role in the production of unsaturated fatty acids, especially in the glia [27]. SREBP-1c and the produced fatty acids in the glia appear to play important roles in myelination, neuronal development, neurite outgrowth, synaptogenesis, and synaptic transmission via glia-neuron interactions [27-29]. Thus, we suggest that the deficiency in SREBP-1c in the current mouse model may have hindered the growth of dendrites in the hippocampus due to deficiencies in fatty-acid production, although the direct connection between SREPB-1c and the morphological alteration is elusive in this study. Further studies are needed to confirm any possible decreases in the neuronal/glial fatty acid content in the hippocampi of SREBP-1c KO mice.

Additionally, we report the alterations in dendritic spine density and proportions of the different spine subtypes (mushroom, stubby, and thin) in KO mice. Although less prevalent than the impairments of the entire dendrite morphology, the dendritic spine densities were significantly reduced in the apical CA3 subregion of the hippocampi of $\mathrm{KO}$ mice. Moreover, the differences in the alterations in the proportions of the spine subtypes were observed in the apical CA1 and CA3 subregions of the KO hippocampi. Dendritic spines constitute the unitary postsynaptic compartment of excitatory connection, and changes in the density and morphology of spines reflect alterations in synaptic strength 
and connectivity, which in turn affect brain functions [30]. In various psychiatric disorders, including autism spectrum disorders, Alzheimer's disease, and schizophrenia, spiny synapses are implicated as important substrates of pathoetiology [31]. The alterations of spine density and morphology in disease-specific brain regions may contribute to abnormalities in selected neural circuits, which in turn may underlie the behavioral deficits of the disorders [31]. In schizophrenia, several clinical studies have reported the reduced spine density in some brain regions, including the dorsolateral prefrontal cortex, superior temporal gyrus, and hippocampal CA3 subregions [32-34]. The shapes of the spines reflect the efficacy and maturity of synapses. In the present study, the decrease in stubby-shaped spines and increase in thin-shaped spines in the apical CA1 and/or CA3 subregions of KO mice, which reflect a decrease in the volume of the spine head, may influence the decrease in the postsynaptic density and changes in excitatory neurotransmission [35]. Furthermore, the increase in thin spines reflects a greater number of immature synapses [36,37]. The suppression of all potential SREBP activities in vivo via the deletion of the SREBP cleavageactivating protein (SCAP) — a post-translational activator of SREBP—in mice increases the number of thin-shaped spines in the CA1 subregion of the hippocampus [38]. In the current study, the impairments of synaptic structures previously elicited by the broader inactivation of all the SREBP isoforms in SCAP-inactivated mice were retained even with the more specific deletion of SREBP-1c. This suggests the vital role of the SREBP-1c isoform in the maintenance of hippocampal postsynaptic sites and preservation of the population of mature spines. Further studies involving hippocampal synaptosomes from WT and $\mathrm{KO}$ mice are warranted to confirm and to elucidate the molecular mechanisms underlying these findings.

Another notable finding in this study is the regional variability of the observed morphological changes. Among the subregions analyzed, CA3 registered the highest degree of changes in the morphological parameters examined. Several clinical and preclinical studies of schizophrenia have also reported morphological alterations of the hippocampal CA3 subregion. Kolomeets et al. [34,39] reported alterations in arborization and a decrease in spine densities, the proportion of mature synapses, and the density of mossy fiber synapses in the CA3 of patients with schizophrenia. In rats prenatally injected with ketamine (a non-competitive inhibitor of glutamate N-methyl-D-aspartate receptors), as animal models of schizophrenia, a significant decrease in the CA3 pyramidal cell layer thickness was reported without changes in cell density [40]. Additionally, the above clinical and animal studies suggest the correlation between the vulnerability of CA3 subregions and behavioral symptoms of schizophrenia. In this study, SREBP-1 expression exhibited the highest degree of reduction in the CA3 subregion of the SREBP-1c KO hippocampi, suggesting that the SREBP-1c isoform, although present in all subregions, was most affected in the CA3 subregion. This may explain the predisposition of the CA3 region, compared with other subregions, to higher degrees of SREBP-1c-related morphological alterations. Congruent structural modifications, although present to a lesser degree, in the CA1 and DG regions might be explained by the intra-hippocampal connectivity between the DG, CA3, and CA1 subregions both anatomically [41] and synaptically (circuitry) [42]. Therefore, any alterations in the signaling of one part might have an overreaching effect on the nearby subregions. Moreover, the remaining SREBP-1 expression present in the hippocampi of SREBP-1c-specific KO mice indirectly represents the remaining proportion of the SREBP-1a isoform in the different subregions. Furthermore, the Srebf-1a mRNA expression significantly increased in the whole hippocampal lysates of SREBP-1c KO mice [20]. Therefore, SREBP-1a might have played a role in mitigating the SREBP-1c-induced structural alterations by providing an alternative, compensatory pathway for the de novo lipid synthesis, as it shares common functions with the SREBP-1c isoform. Therefore, additional research investigating the absence of SREBP-1a or both SREBP-1 isoforms would further elucidate the findings of the current study. Experiments confirming SREBP-1c isoform-specific expressions among the hippocampal subregions and mechanistic pathways involved in the morphological alterations observed are warranted. Nevertheless, the importance of the 
CA3 subregion in both clinical and animal models of schizophrenia-although this varies with specific underlying mechanisms - still provides a sufficient basis for its pronounced susceptibility to alterations in both structural and functional neuroplasticity in the current SREBP-1c KO mice.

The differentially expressed genes and proteins, suggested as novel molecular candidates related to the hippocampal dysfunction of SREBP-1c KO mice in our previous study, may also provide insights into the neuroplastic alterations found in the current study [20]. Glp2r, a gene associated with neuroprotection and neurogenesis [43], and Ndn, a gene associated with neuronal differentiation and survival [44,45] and axonal growth [45], decrease especially in the CA3 pyramidal cell layers of SREBP-1c KO mice [20]. Although the proteins have no known direct physical or functional interactions with SREBP-1 based on a protein-protein interaction network analysis [20], their possible indirect interactions with SREBP-1c and/or other neuroplasticity-related molecules cannot be discounted. Further in-depth analyses involving gene-gene and gene-environment interactions are needed to further demonstrate the extent of signaling pathway involvement.

The observations found in the current study are limited to the hippocampi of 3-4month-old male mice, without any preference for the right or left hippocampus. Some studies have reported sexual dimorphism in the structural [46-48] and neurocognitive [48] alterations found in schizophrenia. Additionally, some studies have reported differences between the structures $[49,50]$ and molecular expressions [51,52] of the left and right hippocampi of patients with schizophrenia. Age-dependent differences in structural changes [53-55] have also been reported in schizophrenia. To ascertain the practicability of using SREBP-1c KO mice as models of schizophrenia or any other neuropsychiatric diseases, the possible sexual dimorphism, asymmetries between the left and right hippocampi, and age dependence should be further investigated.

\section{Materials and Methods}

\subsection{Animals and Treatment}

Three- to four-month-old SREBP-1c KO mice-generous gifts from Dr. Timothy F. Osborne (Sanford Burnham Prebys Medical Discovery Institute, Orlando, FL, USA) - were maintained in a C57BL/6J strain background as previously described $[19,20]$. The animals were housed in standard cages in a specific pathogen-free facility maintained on a $12: 12 \mathrm{~h}$ light/dark cycle at $25^{\circ} \mathrm{C}$. Food and water were provided ad libitum. All experimental and animal handling methods were performed in compliance with the recommendations of the Chonnam National University (6 January 2017; CNU IACUC-YB-2017-01) and the NIH Guide for the Care and Use of Laboratory Animals [56]. All efforts were made to ensure that the number of animals and potential suffering were minimized.

\subsection{Passive Avoidance}

The passive avoidance task employed in this study was performed as outlined in our previous studies [57]. Using a passive avoidance apparatus (UgoBasile, Gemonio, Italy), the test involved training and testing phases that were $24 \mathrm{~h}$ apart. During the training, the mice were allowed to explore the lit chamber for $20 \mathrm{~s}$ before the trap door was opened, and they were given a foot shock ( $0.5 \mathrm{~mA}$ for $2 \mathrm{~s})$ upon their entry to the dark chamber. The mice were kept in the dark chamber for $20 \mathrm{~s}$ before returning them to their home cage. For the testing phase, the mice were placed in the lit chamber again, and the trap door was open after $1 \mathrm{~s}$. The time spent in the lit chamber before entering the dark chamber was recorded as the cross-over latency (s). A limit of $540 \mathrm{~s}$ was set for all mice. Shorter latency rates indicate low retention.

\subsection{Golgi Staining}

Golgi staining was used to visualize the dendritic branching complexity and spines of the neurons in the mice hippocampi. The methods and protocols employed were previously described $[30,58]$. The FD Rapid Golgistain ${ }^{\mathrm{TM}}$ Kit (FD Neurotechnologies, Ellicott City, 
MD, USA) was used, according to the manufacturer's instructions. Briefly, the brains were placed in a Golgi-Cox solution for 14 days before saturation with sucrose solution for 3-7 days at room temperature (RT). The $200 \mu \mathrm{m}$-thick hippocampal sections were prepared on gelatin-coated slides and left to air dry away from light for 1-3 days before processing for Golgi impregnation.

\subsection{Sholl Analysis}

The methods for quantifying dendritic complexity, dendritic length, and the number of branch points were described for our previous studies $[30,58]$ with some modifications. Briefly, Sholl's concentric method [59] used with the ImageJ (National Institutes of Health, Bethesda, MD, USA) program was used to analyze the neuronal tracings visualized by the $200 \times$ Leica DM750 optical microscope (Leica Microsystems, Wetzlar, Germany) and traced using the Leica Application Suite (version 4.12, Leica Microsystems) and Adobe Photoshop CS6 (Adobe Systems, San Jose, CA, USA). Ten neurons per hippocampal subregion were selected from each animal ( $n=4$ /group) using the criteria by Morley et al. [60]: (1) the cell body was in the subregion of interest, (2) the staining of the branches was efficient and complete throughout the length, and (3) the branches were isolated from their neighbors. The concentric circles were laid over the neuron starting from the cell body until the end of the longest dendrite at $10 \mu \mathrm{m}$ intervals, and the number of dendrites intersecting at each circle was analyzed to determine the complexity, length, and branch points.

\subsection{Analysis of Dendritic Diameter}

The dendritic diameters were measured using the ObjectJ plug-in (https:/ / sils.fnwi uva.nl/bcb/objectj; accessed on 29 December 2020) for ImageJ/Fiji [61] software. The dendritic segments were included in the analysis if they were intact, properly stained, and unbranched. Photomicrographs were taken using a light microscope, the Leica DM750 optical microscope (Leica Microsystems), under 1000× magnification. Using ObjectJ, 8 evenly spaced diameter measurements were taken from $10 \mu \mathrm{m}$-long dendritic segments, and 10 segments were analyzed from each animal ( $n=4$ /group). Data are expressed as the mean diameter of 8 readings per $10 \mu \mathrm{m}$ dendritic segments.

\subsection{Analysis of Dendritic Spine Density and Morphology}

The measurement of dendritic spine density and morphology was performed according to our previous studies [20,58]. Briefly, all protruding dendritic spines were counted on $30 \mu \mathrm{m}$ dendritic segments. As in Section 4.4, only intact, properly stained, and unbranched dendritic segments were included in the analyses under $1000 \times$ magnification. The spines were further classified into different morphological subtypes based on criteria by Chakraborti et al. [62]: (1) thin: spines with distinct small heads and elongated necks; (2) mushroom: spines with large heads and distinct necks; and (3) stubby: very short spines with overall stubby appearances and no distinguishable necks. Ten segments were counted from each animal ( $n=4$ /group), and spine density was computed as the number of spines per $10 \mu \mathrm{m}$ of dendritic length.

\subsection{Immunofluorescence of Free-Floating Sections}

The immunofluorescence protocol was based on our previous study with some modifications [58]. The brains were collected and perfused with $4 \%(w / v)$ paraformaldehyde (Sigma-Aldrich, St. Louis, MO, USA) and transferred into 30\% (w/v) sucrose solution for 4 days, and $30 \mu \mathrm{m}$-thick coronal sections were made using a frozen sliding microtome (SM2010R; Leica Microsystems) at around $-2.06 \mathrm{~mm}$ relative to the bregma. Endogenous hydrogen peroxidase activity was neutralized through incubation of the sections in $0.3 \%$ $(v / v)$ hydrogen peroxide in distilled water for $20 \mathrm{~min}$. The sections were blocked with $5 \%$ $(v / v)$ normal goat serum (Vector ABC Elite Kit; Vector Laboratories, Burlingame, CA, USA) plus $1 \%$ bovine serum albumin (Sigma-Aldrich) in phosphate-buffered saline ( $\mathrm{pH} 7.4$ ) with $0.3 \%(v / v)$ Triton $\mathrm{X}-100$ for $1 \mathrm{~h}$ at RT. The sections were incubated with primary 
antibodies, rabbit anti-SREBP-1 (1:100; Abcam, Cambridge, UK) and mouse anti-neuronal nuclei (NeuN; 1:100; Merck Millipore, Billerica, MA, USA), diluted in antibody dilution buffer (Invitrogen, Carlsbad, CA, USA) overnight at $4{ }^{\circ} \mathrm{C}$. After thorough washing, the sections were incubated in secondary antibodies, goat anti-rabbit IgG (1:500; Alexa-Fluor 488; Invitrogen) or goat anti-mouse IgG (1:500; Alexa-Fluor 594; Invitrogen), for $1 \mathrm{~h}$ at RT. The nuclei were counterstained with 4',6-diamidino-2-phenylindole (1:200; Thermo Fisher Scientific, Waltham, MA, USA) for $30 \mathrm{~min}$ at RT. The immunoreactivities of SREBP-1 in the CA1, CA3, and DG subregions of the hippocampus were analyzed with ImageJ/Fiji software [61] ( $n=5$ mice/group).

\subsection{Analysis of Differences in the Degree of Morphological Alterations in Each Hippocampal Subregion}

The values of $\log 2$ fold changes in the total length, number of branch points, diameter, and spine densities of the dendrites in each $\mathrm{KO}$ hippocampal subregion relative to the WT subregion were obtained and statistically analyzed using Prism (GraphPad Software, San Diego, CA, USA).

\subsection{Statistical Analyses}

All statistical analyses were performed using Prism (GraphPad Software, San Diego, CA, USA). To identify the differences between the cross-over latencies during the passive avoidance tests and the dendritic complexities of the WT and $\mathrm{KO}$ groups and the log2 fold changes in the morphological parameters among subregions, two-way repeated-measures ANOVA was performed followed by multiple comparison tests corrected with Šidăk's post hoc test for 8 animals and 40 neurons per group, respectively. Unpaired Student's $t$-tests were used for all other experiments to compare the means of the WT and KO groups. The normality of the data distribution was analyzed using the Shapiro-Wilk test. For all the statistical tests, a p-value of less than 0.05 was considered statistically significant. All the exact $\mathrm{p}$-values are reported in the Results section. Power analysis to determine the minimum required sample size per group was performed at an alpha level of 0.05 to achieve a power of at least $90 \%$ using La Morte's power calculator [63]. The minimum required sample sizes obtained using this method were as follows: 8 mice for the passive avoidance test; 40 neurons for dendritic complexity, dendritic length, dendritic branch points, dendritic diameter, spine density, and spine morphology experiments; and 5 mice for the relative staining intensity values obtained from immunofluorescence experiments. The exact sample sizes used per experiment are reported in the Results section, figures, and figure legends.

\section{Conclusions}

In summary, the present study assessed the impairment of neuroplasticity in the hippocampus of SREBP-1c KO mice, with emphasis on structural changes. Independent of the specific underlying mechanisms yet to be ascertained, the evidence of the possible interplay between the CA3 region-specific (1) increase in morphological alterations and impairments, (2) decrease in SREBP-1 expression, and (3) schizophrenia-like behaviorrelated mechanisms is presented. Thus, the potential usefulness of SREBP-1c KO mice as animal models of schizophrenia has been emphasized. Furthermore, this study improves our understanding of the critical role of SREBP-1c in maintaining the normal architecture and functioning of the mouse hippocampus.

Author Contributions: Conceptualization, C.M.; methodology, M.J.A., S.L., M.W., P.D.E.W.-M., S.H.K., T.S., T.-I.J., S.-S.I. and C.M.; validation, M.J.A., M.W. and P.D.E.W.-M.; formal analysis, M.J.A. and S.L.; investigation, M.J.A. and S.L.; resources, S.-H.K., T.S., T.-I.J., S.-S.I. and C.M.; data curation, M.J.A., S.L. and C.M.; visualization, M.J.A., S.L. and C.M.; writing-original draft preparation, M.J.A. and S.L.; writing-review and editing, M.J.A., S.L. and C.M.; supervision, C.M.; project administration, C.M.; funding acquisition, C.M. All authors have read and agreed to the published version of the manuscript. 
Funding: This work was supported by the National Research Foundation (NRF) of Korea grant funded by the Korean Government (NRF-2016R1D1A1B03933836; NRF-2019R1A2C1004045).

Institutional Review Board Statement: The study was conducted according to the guidelines of the Declaration of Helsinki, and approved by the Ethics Committee of Chonnam National University (CNU IACUC-YB-2017-01; 6 January 2017).

Informed Consent Statement: Not applicable.

Data Availability Statement: This paper utilized original data not used in other publications. The datasets generated and/or analyzed in the present study are available from the corresponding author upon reasonable request.

Conflicts of Interest: The authors declare no conflict of interest.

\section{References}

1. Dhuriya, Y.K.; Sharma, D. Neuronal plasticity: Neuronal organization is associated with neurological disorders. J. Mol. Neurosci. 2020, 70, 1684-1701. [CrossRef]

2. Gonçalves, J.T.; Schafer, S.T.; Gage, F.H. Adult neurogenesis in the hippocampus: From stem cells to behavior. Cell. 2016, 167, 897-914. [CrossRef]

3. França, T.F.A. Plasticity and redundancy in the integration of adult born neurons in the hippocampus. Neurobiol. Learn. Mem. 2018, 155, 136-142. [CrossRef] [PubMed]

4. Jeffery, K.J. The hippocampus: From memory, to map, to memory map. Trends Neurosci. 2018, 41, 64-66. [CrossRef]

5. Haukvik, U.K.; Tamnes, C.K.; Söderman, E.; Agartz, I. Neuroimaging hippocampal subfields in schizophrenia and bipolar disorder: A systematic review and meta-analysis. J. Psychiatr. Res. 2018, 104, 217-226. [CrossRef]

6. Heckers, S. Neuroimaging studies of the hippocampus in schizophrenia. Hippocampus 2001, 11, 520-528. [CrossRef]

7. Harrison, P.J. The hippocampus in schizophrenia: A review of the neuropathological evidence and its pathophysiological implications. Psychopharmacology 2004, 174, 151-162. [CrossRef]

8. Gothelf, D.; Soreni, N.; Nachman, R.P.; Tyano, S.; Hiss, Y.; Reiner, O.; Weizman, A. Evidence for the involvement of the hippocampus in the pathophysiology of schizophrenia. Eur. Neuropsychopharmacol. 2000, 10, 389-395. [CrossRef]

9. Heckers, S.; Konradi, C. Hippocampal pathology in schizophrenia. Curr. Top. Behav. Neurosci. 2010, 4, 529-553. [CrossRef]

10. Bazan, N.G. Lipid signaling in neural plasticity, brain repair, and neuroprotection. Mol. Neurobiol. 2005, 32, 89-103. [CrossRef]

11. Dietschy, J.M.; Turley, S.D. Thematic review series: Brain Lipids. Cholesterol metabolism in the central nervous system during early development and in the mature animal. J. Lipid Res. 2004, 45, 1375-1397. [CrossRef] [PubMed]

12. Edmond, J.; Higa, T.A.; Korsak, R.A.; Bergner, E.A.; Lee, W.N. Fatty acid transport and utilization for the developing brain. J. Neurochem. 1998, 70, 1227-1234. [CrossRef]

13. Shimano, H. SREBPs: Physiology and pathophysiology of the SREBP family. FEBS J. 2009, 276, 616-621. [CrossRef] [PubMed]

14. Eberle, D.; Hegarty, B.; Bossard, P.; Ferre, P.; Foufelle, F. SREBP transcription factors: Master regulators of lipid homeostasis. Biochimie 2004, 86, 839-848. [CrossRef]

15. Hua, X.; Wu, J.; Goldstein, J.L.; Brown, M.S.; Hobbs, H.H. Structure of the human gene encoding sterol regulatory element binding protein-1 (SREBF1) and localization of SREBF1 and SREBF2 to chromosomes 17p11.2 and 22q13. Genomics 1995, 25, 667-673. [CrossRef]

16. Miserez, A.R.; Cao, G.; Probst, L.C.; Hobbs, H.H. Structure of the human gene encoding sterol regulatory element binding protein 2 (SREBF2). Genomics 1997, 40, 31-40. [CrossRef]

17. Shimomura, I.; Shimano, H.; Horton, J.D.; Goldstein, J.L.; Brown, M.S. Differential expression of exons 1a and 1c in mRNAs for sterol regulatory element binding protein-1 in human and mouse organs and cultured cells. J. Clin. Investig. 1997, 99, 838-845. [CrossRef]

18. Brown, M.S.; Goldstein, J.L. The SREBP pathway: Regulation of cholesterol metabolism by proteolysis of a membrane-bound transcription factor. Cell 1997, 89, 331-340. [CrossRef]

19. Lee, S.; Kang, S.; Ang, M.J.; Kim, J.; Kim, J.C.; Kim, S.H.; Jeon, T.I.; Jung, C.; Im, S.S.; Moon, C. Deficiency of sterol regulatory element-binding protein-1c induces schizophrenia-like behavior in mice. Genes Brain Behav. 2019, 18, e12540. [CrossRef]

20. Ang, M.J.; Kim, J.; Lee, S.; Kim, S.-H.; Kim, J.-C.; Jeon, T.-I.; Im, S.-S.; Moon, C. Transcriptome profiling reveals novel candidate genes related to hippocampal dysfunction in SREBP-1c knockout mice. Int. J. Mol. Sci. 2020, 21, 4131. [CrossRef]

21. Carbon, M.; Correll, C.U. Thinking and acting beyond the positive: The role of the cognitive and negative symptoms in schizophrenia. CNS Spectr. 2014, 19 (Suppl. 1), 38-52. [CrossRef]

22. Rosoklija, G.; Toomayan, G.; Ellis, S.P.; Keilp, J.; Mann, J.J.; Latov, N.; Hays, A.P.; Dwork, A.J. Structural abnormalities of subicular dendrites in subjects with schizophrenia and mood disorders: Preliminary findings. Arch. Gen. Psychiatry 2000, 57, 349-356. [CrossRef] [PubMed]

23. Moyer, C.E.; Shelton, M.A.; Sweet, R.A. Dendritic spine alterations in schizophrenia. Neurosci. Lett. 2015, 601, 46-53. [CrossRef]

24. Akum, B.F.; Chen, M.; Gunderson, S.I.; Riefler, G.M.; Scerri-Hansen, M.M.; Firestein, B.L. Cypin regulates dendrite patterning in hippocampal neurons by promoting microtubule assembly. Nat. Neurosci. 2004, 7, 145-152. [CrossRef] [PubMed] 
25. Li, Z.; Van Aelst, L.; Cline, H.T. Rho GTPases regulate distinct aspects of dendritic arbor growth in Xenopus central neurons in vivo. Nat. Neurosci. 2000, 3, 217-225. [CrossRef]

26. Hoogenraad, C.C.; Milstein, A.D.; Ethell, I.M.; Henkemeyer, M.; Sheng, M. GRIP1 controls dendrite morphogenesis by regulating EphB receptor trafficking. Nat. Neurosci. 2005, 8, 906-915. [CrossRef]

27. Camargo, N.; Smit, A.B.; Verheijen, M.H. SREBPs: SREBP function in glia-neuron interactions. FEBS J. 2009, $276,628-636$. [CrossRef]

28. Nieweg, K.; Schaller, H.; Pfrieger, F.W. Marked differences in cholesterol synthesis between neurons and glial cells from postnatal rats. J. Neurochem. 2009, 109, 125-134. [CrossRef] [PubMed]

29. Rodríguez-Rodríguez, R.A.; Tabernero, A.; Velasco, A.; Lavado, E.M.; Medina, J.M. The neurotrophic effect of oleic acid includes dendritic differentiation and the expression of the neuronal basic helix-loop-helix transcription factor NeuroD2. J. Neurochem. 2004, 88, 1041-1051. [CrossRef] [PubMed]

30. Kang, S.; Lee, S.; Kim, J.; Kim, J.-C.; Kim, S.-H.; Son, Y.; Shin, T.; Youn, B.; Kim, J.-S.; Wang, H. Chronic treatment with combined chemotherapeutic agents affects hippocampal micromorphometry and function in mice, independently of neuroinflammation. Exp. Neurobiol. 2018, 27, 419. [CrossRef] [PubMed]

31. Penzes, P.; Cahill, M.E.; Jones, K.A.; VanLeeuwen, J.-E.; Woolfrey, K.M. Dendritic spine pathology in neuropsychiatric disorders. Nat. Neurosci. 2011, 14, 285-293. [CrossRef] [PubMed]

32. Glantz, L.A.; Lewis, D.A. Decreased dendritic spine density on prefrontal cortical pyramidal neurons in schizophrenia. Arch. Gen. Psychiatry 2000, 57, 65-73. [CrossRef]

33. Sweet, R.A.; Henteleff, R.A.; Zhang, W.; Sampson, A.R.; Lewis, D.A. Reduced dendritic spine density in auditory cortex of subjects with schizophrenia. Neuropsychopharmacology 2009, 34, 374-389. [CrossRef]

34. Kolomeets, N.S.; Orlovskaya, D.D.; Rachmanova, V.I.; Uranova, N.A. Ultrastructural alterations in hippocampal mossy fiber synapses in schizophrenia: A postmortem morphometric study. Synapse 2005, 57, 47-55. [CrossRef] [PubMed]

35. Koyama, Y.; Hattori, T.; Nishida, T.; Hori, O.; Tohyama, M. Alterations in dendrite and spine morphology of cortical pyramidal neurons in DISC1-binding zinc finger protein (DBZ) knockout mice. Front. Neuroanat. 2015, 9, 52. [CrossRef]

36. Konur, S.; Rabinowitz, D.; Fenstermaker, V.L.; Yuste, R. Systematic regulation of spine sizes and densities in pyramidal neurons. J. Neurobiol. 2003, 56, 95-112. [CrossRef]

37. Toni, N.; Teng, E.M.; Bushong, E.A.; Aimone, J.B.; Zhao, C.; Consiglio, A.; van Praag, H.; Martone, M.E.; Ellisman, M.H.; Gage, F.H. Synapse formation on neurons born in the adult hippocampus. Nat. Neurosci. 2007, 10, 727-734. [CrossRef] [PubMed]

38. van Deijk, A.L.F.; Camargo, N.; Timmerman, J.; Heistek, T.; Brouwers, J.F.; Mogavero, F.; Mansvelder, H.D.; Smit, A.B.; Verheijen, M.H. Astrocyte lipid metabolism is critical for synapse development and function in vivo. Glia 2017, 65, 670-682. [CrossRef]

39. Kolomeets, N.S.; Orlovskaya, D.D.; Uranova, N.A. Decreased numerical density of CA3 hippocampal mossy fiber synapses in schizophrenia. Synapse 2007, 61, 615-621. [CrossRef]

40. Coronel-Oliveros, C.M.; Pacheco-Calderón, R. Prenatal exposure to ketamine in rats: Implications on animal models of schizophrenia. Dev. Psychobiol. 2018, 60, 30-42. [CrossRef] [PubMed]

41. Amaral, D.G.; Witter, M.P. The three-dimensional organization of the hippocampal formation: A review of anatomical data. Neuroscience 1989, 31, 571-591. [CrossRef]

42. Brivanlou, I.H.; Dantzker, J.L.; Stevens, C.F.; Callaway, E.M. Topographic specificity of functional connections from hippocampal CA3 to CA1. Proc. Natl. Acad. Sci. USA 2004, 101, 2560-2565. [CrossRef]

43. Xie, Y.-C.; Yao, Z.-H.; Yao, X.-L.; Pan, J.-Z.; Zhang, S.-F.; Zhang, Y.; Hu, J.-C. Glucagon-like peptide-2 receptor is involved in spatial cognitive dysfunction in rats after chronic cerebral hypoperfusion. J. Alzheimer. Dis. 2018, 66, 1559-1576. [CrossRef]

44. Kobayashi, M.; Taniura, H.; Yoshikawa, K. Ectopic expression of necdin induces differentiation of mouse neuroblastoma cells. J. Biol. Chem. 2002, 277, 42128-42135. [CrossRef]

45. Takazaki, R.; Nishimura, I.; Yoshikawa, K. Necdin is required for terminal differentiation and survival of primary dorsal root ganglion neurons. Exp. Cell Res. 2002, 277, 220-232. [CrossRef] [PubMed]

46. Abel, K.M.; Drake, R.; Goldstein, J.M. Sex differences in schizophrenia. Int. Rev. Psychiatry 2010, 22, 417-428. [CrossRef]

47. Nopoulos, P.; Flaum, M.; Andreasen, N.C. Sex differences in brain morphology in schizophrenia. Am. J. Psychiatry 1997, 154, 1648-1654. [CrossRef] [PubMed]

48. Mendrek, A.; Mancini-Marie, A. Sex/gender differences in the brain and cognition in schizophrenia. Neurosci. Biobehav. Rev. 2016, 67, 57-78. [CrossRef] [PubMed]

49. Zaidel, D.W.; Esiri, M.M.; Harrison, P.J. Size, shape, and orientation of neurons in the left and right hippocampus: Investigation of normal asymmetries and alterations in schizophrenia. Am. J. Psychiatry 1997, 154, 812-818. [CrossRef]

50. Zheng, F.; Li, C.; Zhang, D.; Cui, D.; Wang, Z.; Qiu, J. Study on the sub-regions volume of hippocampus and amygdala in schizophrenia. Quant. Imaging Med. Surg. 2019, 9, 1025. [CrossRef]

51. Geddes, A.E.; Huang, X.-F.; Newell, K.A. GluN 2 B protein deficits in the left, but not the right, hippocampus in schizophrenia. BMC Psychiatry. 2014, 14, 1-7. [CrossRef] [PubMed]

52. Delamillieure, P.; Constans, J.M.; Fernandez, J.; Brazo, P.; Benali, K.; Courthéoux, P.; Thibaut, F.; Petit, M.; Dollfus, S. Proton magnetic resonance spectroscopy (1H MRS) in schizophrenia: Investigation of the right and left hippocampus, thalamus, and prefrontal cortex. Schizophre. Bull. 2002, 28, 329-339. [CrossRef] 
53. Chiapponi, C.; Piras, F.; Fagioli, S.; Girardi, P.; Caltagirone, C.; Spalletta, G. Hippocampus age-related microstructural changes in schizophrenia: A case-control mean diffusivity study. Schizophr. Res. 2014, 157, 214-217. [CrossRef]

54. Pujol, N.; Penadés, R.; Junqué, C.; Dinov, I.; Fu, C.; Catalán, R.; Ibarretxe-Bilbao, N.; Bargalló, N.; Bernardo, M.; Toga, A. Hippocampal abnormalities and age in chronic schizophrenia: Morphometric study across the adult lifespan. Br. J. Psychiatry. 2014, 205, 369-375. [CrossRef]

55. Thoma, R.J.; Monnig, M.; Hanlon, F.M.; Miller, G.A.; Petropoulos, H.; Mayer, A.R.; Yeo, R.; Euler, M.; Lysne, P.; Moses, S.N. Hippocampus volume and episodic memory in schizophrenia. J. Int. Neuropsychol. Soc. 2009, 15, 182. [CrossRef]

56. National Research Council. Guide for the Care and Use of Laboratory Animals, 8th ed.; The National Academies Press: Washington, DC, USA, 2011. [CrossRef]

57. Kim, J.-S.; Lee, H.-J.; Kim, J.C.; Kang, S.S.; Bae, C.-S.; Shin, T.; Jin, J.-K.; Kim, S.H.; Wang, H.; Moon, C. Transient impairment of hippocampus-dependent learning and memory in relatively low-dose of acute radiation syndrome is associated with inhibition of hippocampal neurogenesis. J. Radiat. Res. 2008, 49, 517-526. [CrossRef] [PubMed]

58. Ang, M.J.; Kang, S.; Moon, C. Melatonin alters neuronal architecture and increases cysteine-rich protein 1 signaling in the male mouse hippocampus. J. Neurosci. Res. 2020, 98, 2333-2348. [CrossRef]

59. Sholl, D.A. Dendritic organization in the neurons of the visual and motor cortices of the cat. J. Anat. 1953, 87, 387-406. [PubMed]

60. Morley, B.J.; Mervis, R. Dendritic spine alterations in the hippocampus and parietal cortex of alpha7 nicotinic acetylcholine receptor knockout mice. Neuroscience 2013, 233, 54-63. [CrossRef]

61. Schindelin, J.; Arganda-Carreras, I.; Frise, E.; Kaynig, V.; Longair, M.; Pietzsch, T.; Preibisch, S.; Rueden, C.; Saalfeld, S.; Schmid, B. Fiji: An open-source platform for biological-image analysis. Nat. Methods 2012, 9, 676-682. [CrossRef] [PubMed]

62. Chakraborti, A.; Allen, A.; Allen, B.; Rosi, S.; Fike, J.R. Cranial irradiation alters dendritic spine density and morphology in the hippocampus. PLoS ONE 2012, 7, e40844. [CrossRef] [PubMed]

63. Boston University Research Support. La Morte's Power Calculator. Available online: https://www.bu.edu/researchsupport/ compliance/animal-care/working-with-animals/research/sample-size-calculations-iacuc/ (accessed on 15 April 2021). 